\title{
SORO DE LEITE COM HIDRÓLISE DA LACTOSE: DESAFIOS NA SECAGEM
}

\section{Lactose hydrolyzed whey: drying challenges}

\author{
Valéria Maria dos Santos ${ }^{1}$, Elisângela Ramieres Gomes ${ }^{1}$, Virgínia Nardy Paiva ${ }^{1}$, Rodrigo \\ Stephani ${ }^{2}$, Antônio Fernandes de Carvalho ${ }^{l}$, Ítalo Tuler Perrone ${ }^{3^{*}}$
}

\begin{abstract}
RESUMO
Para atender a demanda de consumidores que buscam por produtos sem lactose ou com baixo teor de lactose, as indústrias têm diversificado sua gama de produtos ao longo dos anos. Vários produtos lácteos deslactosados já estão bem estabelecidos no mercado, como: leite UHT, iogurte e queijo. Este último possui o soro como seu derivado que é muito utilizado como ingrediente na indústria de alimentos. No entanto, ainda que este mercado venha crescendo, o mesmo apresenta desafios tecnológicos na secagem, transporte e estocagem de alguns produtos como o soro deslactosado. O soro tradicional é um produto de difícil manutenção do estado amorfo, com isso, problemas tecnológicos como empedramento e aderência ao equipamento podem ocorrer. A hidrolise da lactose, promove a liberação de glicose e galactose no leite. Estes monossacarídeos possuem temperatura de transição vítrea menor que a da lactose, favorecendo a transição durante o processamento ou a estocagem. Dessa forma, o soro deslactosado torna-se ainda mais difícil de secar. Com isso, as indústrias têm buscado quais os melhores parâmetros de operação para secagem, juntamente com modificações na composição que favoreçam a manutenção do estado vítreo do soro deslactosado.

Palavras-chave: lactase; transição vítrea; secagem por pulverização; aglomeração.

1 Universidade Federal de Viçosa, Departamento de Tecnologia de Alimentos (DTA), INOVALEITE, Viçosa, MG, Brasil

2 Universidade Federal de Juiz de Fora, Departamento de Química (DQ) - QUIMTEC, Juiz de Fora, MG, Brasil.

3 Universidade Federal de Juiz de Fora,Departamento de Ciências Farmacêuticas, Faculdade de Farmácia. Campus Universitário, Rua José Lourenço Kelmer, s/n, São Pedro, 36036-330, Juiz de Fora, MG, Brasil. E-mail: italotulerperrone@gmail.com

* Autor para correspondência.
\end{abstract}

Recebido / Received: 27/04/2018

Aprovado / Approved: 24/08/2018 


\begin{abstract}
The industry has diversified its range of products over the years to meet the demand of consumers for lactose-free or low-lactose products. Several lactosefree dairy products are already well established in the market, such as UHT milk, yogurt and cheese. The latter has the whey as its derivative which is widely used as an ingredient in the food industry. However, the market of lactose-free products presents technological challenges in drying, transport and storage of some products such as whey. Technological problems like pavement and adhesion to the equipment can occur because traditional whey is a product of difficult maintenance of the glass transition. The lactose hydrolysis promotes the release of glucose and galactose in milk. These two sugars have a lower glass transition than lactose, causing a reduction of the glass transition in the lactose-free product. Therefore, the lactose-free whey becomes even more difficult to dry compared to whey with intact lactose. Thus, the industries have sought the best operating parameters for drying, combined with modifications in the composition, favoring the maintenance of the vitreous state of the delactosed whey.
\end{abstract}

Keywords: lactase; glass transition; spray drying; caking.

\section{INTRODUÇÃO}

De acordo com Lule et al. (2016), cerca de $70 \%$ da população mundial adulta apresenta intolerância a lactose. Esta é designada pela deficiência da enzima $\beta$-galactosidase (lactase) em humanos podendo levar a um desconforto gastrointestinal ao consumir produtos que contêm lactose, com isso, produtos lácteos têm sido evitados na dieta de muitos. Para atender as necessidades dos consumidores que apresentam essa condição de intolerância aliado à importância do valor nutricional dos produtos lácteos fomentou-se a fabricação de produtos sem lactose ou com baixo teor de lactose (RONG et al., 2011; BAILEY et al., 2013; TROISE et al., 2016).

Para aumentar a gama de lácteos sem lactose ou com baixo teor de lactose no mercado, as indústrias de laticínios têm utilizado estratégias de produção através da filtração por membranas técnicas que consiste na remoção física da lactose do leite ou por métodos de hidrólise enzimática (LULE et al., 2016).
Em muitos países, produtos com baixo teor de lactose (também conhecidos como deslactosados) já estão firmemente inseridos no mercado, tais como iogurte, leite UHT e queijo (ADHIKARI et al., 2010; RUIZ et al., 2012; MILKOVSKA; HOFFMANN, 2017; MOREIRA et al., 2017). Este último possui como seu derivado o soro, que é amplamente utilizado como ingrediente ou como precursor de ingredientes nas indústrias alimentícias (GERNIGON et al., 2010).

Mesmo diante desse cenário de crescimento e diversificação de produtos deslactosados, este mercado apresenta desafios tecnológicos no processo de secagem, transporte e estocagem de alguns produtos como o soro deslactosado. O soro é um produto de difícil manutenção do estado vítreo, principalmente o soro ácido deslactosado, podendo levar à aderência do pó no equipamento e empedramento (PERRONE et al., 2011; PERRONE et al., 2013; ALVES et al., 2014; PERRONE et al., 2016).

A manutenção do estado vítreo é imprescindível para a produção de lácteos desi- 
dratados, sendo que, a composição do produto, temperatura de transição vítrea, parâmetros de secagem e propriedades do pó exercem uma função fundamental na produção desses lácteos. (SCHUCK et al., 2009; CARPIN et al., 2016; PERRONE et al., 2016; SADEK et al., 2016; SCHUCK et al., 2016; NORWOOD et al., 2017).

\section{REFERENCIAL TEÓRICO}

O processo de secagem por atomização é muito eficaz e utilizado na conservação dos alimentos, isso porque consiste na remoção parcial da água, e consequentemente, diminui a atividade de água do produto, podendo ser armazenados à temperatura ambiente. Além disso, a secagem é utilizada também para estabilização de constituintes e emulsões e microencapsulação de microrganismos, enzimas e moléculas (MASTERS, 2002; NOELLO et. al., 2016; SÁNCHEZ et. al., 2016; JANISZEWSKA-TURAK, 2017).

A técnica de secagem industrial do leite é utilizada desde o início do século XX. O processo de secagem por spray dryer foi primeiramente descrito em 1865 para uso de processamento de ovos e a primeira patente foi oficializada em 1872. A partir de 1920 foram consolidadas as primeiras aplicações industriais da secagem por spray dryer, sendo empregadas às indústrias de detergentes, de lácteos e no preparo dos primeiros compostos encapsulados. Atualmente, a aplicação da secagem por atomização é utilizada para vários tipos de alimentos, como bebidas, proteínas vegetais, extratos de frutas e vegetais, carboidratos, extratos de chá, dentre outros (MASTERS, 1980; DZIEZAK, 1987; MASTERS, 2002; SANTOS, 2014).

O processo de secagem por spray dryer demanda um alto custo econômico, dessa forma, o líquido é concentrado em um evaporador a vácuo antes da etapa da secagem. A concentração a vácuo consiste na remoção da água por meio do fornecimento de energia na forma de calor ao produto. A evaporação é realizada numa pressão inferior à pressão atmosférica, o que permite que a concentração ocorra em temperaturas entre $40^{\circ} \mathrm{C}$ e $75{ }^{\circ} \mathrm{C}$, minimizando os danos térmicos aos constituintes do alimento (CARIC et al., 2009; PATEL et al., 2010).

A secagem por atomização é um processo rápido em que, o líquido concentrado é atomizado em pequenas gotículas, o que faz com que ocorra um aumento da área superficial favorecendo a troca de calor e massa. Essas gotículas entram em contato com o ar de secagem de baixa umidade relativa e alta temperatura (média de $200{ }^{\circ} \mathrm{C}$ ), ocorrendo assim a evaporação até que o teor de umidade da partícula esteja muito baixo, o que faz com que interrompa o processo de difusão das moléculas por meio da superfície seca da partícula. Após, o pó seco é recuperado no ciclone ou no saco de filtro (KESHANI et al., 2013; MUJUMDAR, 2014; SCHUCK et al., 2016a).

A posição do atomizador no tocante à entrada de ar de secagem determina o contato de pulverização. Na secagem por atomização, o fluxo é em co-corrente, ou seja, o produto é aspergido em sentido co-corrente com o ar quente empregado na secagem. A evaporação é rápida e, conforme o ar de secagem esfria, o tempo de evaporação é reduzido. Assim, o produto é preservado da ação e degradação do calor. A temperatura do pó varia, geralmente, de $10{ }^{\circ} \mathrm{C}$ a $20^{\circ} \mathrm{C}$ abaixo da temperatura do ar de saída que é, em média, $90{ }^{\circ} \mathrm{C}$ (KESHANI, 2013; SCHUCK, 2016b).

A formação de gotículas por atomização é uma etapa crítica, visto que, influencia diretamente o diâmetro e a porosidade das partículas obtidas (SANDER; PENOVIĆ, 2014). A distribuição do diâmetro das partículas, por sua vez, influencia o tempo de residência e as taxas de secagem que podem impactar a estrutura física da partícula (POOZESH et al., 2017). 
A secagem por spray dryer pode sofrer influência de diversos fatores como: velocidade do ar de secagem; umidade e temperatura do ar de entrada; taxa de fluxo de alimentação e concentração; propriedades reológicas; propriedades termodinâmicas e especificações do atomizador. Um dos desafios de processamento em secadores por atomização é a deposição de partículas do pó na parede da câmara que, além de ter uma perda de massa do produto final, implica diretamente na qualidade do produto por meio da degradação das partículas depositadas. Dessa forma, devem-se definir as melhores condições de operação do spray dryer que minimizem a deposição dos pós nas paredes da câmara de secagem (KESHANI et al., 2015).

De acordo com Schuck (2002), não há um equilíbrio real entre a umidade do ar e da partícula, visto que, o produto permanece na câmara de secagem num período de processamento muito curto, estando em torno de 20 a 60 segundos. Com isso, deve-se utilizar como atributo principal de controle a atividade de água do produto seco, ajustando um valor de atividade de água desejado no produto, e por fim, controlar as condições de operações de secagem por meio da determinação da umidade relativa do ar de saída da câmara (SCHUCK et al., 2008).

É possível controlar algumas propriedades fundamentais do produto final como forma e distribuição de tamanho de partículas do pó que variam de $20 \mu \mathrm{m}$ a $150 \mu \mathrm{m}$; densidade; teor de ar ocluso; teor de umidade e temperatura do pó a partir do monitoramento automático dos parâmetros de secagem durante o processo de secagem por atomização. (CARIC et al., 2009).

Os produtos desidratados apresentam desafios tecnológicos que podem ser associados à transição vítrea $(\mathrm{Tg})$. Essa transição se refere a uma transformação do estado vítreo (líquido de alta viscosidade) para o estado gomoso (líquido de baixa viscosidade), sendo esta transição reversível e realiza-se a uma determinada temperatura definida como temperatura de transição vítrea (TTg) (SCHUCK et al., 2005; PERRONE et al., 2016).

A secagem por atomização produz pós com estruturas amorfas secas, que podem apresentar-se no estado vítreo, na qual as moléculas não possuem mobilidade segmentar, mas vibram levemente, devido a alta viscosidade da solução (BRENNAN et al., 1971) e também podem estar no estado gomoso, que é um estado emborrachado na qual as moléculas se tornam mais macias e flexíveis devido a menor viscosidade que a solução apresenta, permitindo maior mobilidade molecular (BHANDARI et al., 1997; AGUILERA e LILLFORD, 2007; WOO et al., 2009a). Ao atingir uma temperatura acima da sua temperatura de transição vítrea (TTg), as estruturas amorfas passam do estado vítreo para o estado gomoso, sucedendo a mudanças estruturais indesejáveis como aglomeração do pó, adesão ao equipamento e empedramento (LEITE et al., 2005).

Em produtos lácteos na forma de pó, a lactose se encontra no estado amorfo devido a secagem, que, por ser um processo rápido, não possui tempo de ocorrer a estabilização das moléculas e haver a cristalização da lactose. Dessa forma, esses pós exibem transição vítrea se atingir a uma temperatura acima da TTg. A temperatura de transição vítrea não é igual à temperatura de aderência do pó na câmara de secagem, assim sendo, para ocorrer o fenômeno de aderência, é preciso alcançar temperaturas de 20 a $25{ }^{\circ} \mathrm{C}$ acima da temperatura de transição vítrea (TTg) (REFSTRUP, BONKE, 2011).

Ao submeter o produto em pó a uma temperatura acima da sua TTg, acarretará em várias alterações, como: aumento de volume livre, diminuição da viscosidade, variação do calor específico e incremento da expansão térmica (ROOS, 1993; SCHUCK, 
2016b). Esses fatores regem uma sucessão de modificações estruturais dependentes do tempo, podendo levar a aglomeração dos pós, aderência e empedramento durante o processamento, transporte e estocagem (FITZPATRICK et al., 2007).

Para a produção do soro em pó tradicional, pode ser utilizada uma combinação de processos tais como filtração de membranas, evaporação a vácuo e secagem em spray dryer. A fim de evitar aglomeração e aderência do mesmo no equipamento, é necessário que haja a cristalização da lactose em soro de leite concentrado precedente ao processo de secagem por atomização (SCHUCK et al., 2004; CARPIN et al., 2016). Esta cristalização aumenta a temperatura de aderência do pó, e consequentemente, diminui a aglomeração e viscosidade no interior da câmara (HYND, 1980). Todavia, a cristalização da lactose diminui a retenção do soro em pó (LI et al., 2016).

No entanto, os parâmetros adotados no processo de secagem para o soro tradicional se tornam inadequado para a produção do soro em pó deslactosado, uma vez que, para obtenção do soro deslactosado, tem-se a hidrólise da lactose que promove a liberação de glicose e galactose. E esses monossacarídeos possuem uma TTg inferior a da lactose, o que diminui a temperatura de transição vítrea do soro (SCHUCK et al., 2005). Além disso, é mais difícil ocorrer a cristalização desses monossacarídeos, visto que, apresentam maior entalpia de ativação dos cristais sendo necessário um alto valor de energia cinética para vencer a barreira energética e assim cristalizar (DAS et al., 2014). Dessa forma, o método de cristalização utilizado para a secagem do soro tradicional não se adapta ao processo de secagem do soro deslactosado. Logo, esses produtos apresentam diferentes comportamentos no processo de secagem, transporte e estocagem.

A Tabela 1 apresenta a temperatura de transição vítrea dos constituintes do soro deslactosado (SCHUCK et al., 2005).

Tabela 1 - Temperatura de transição vítrea dos constituintes do soro deslactosado

\begin{tabular}{cc}
\hline Componentes & $\begin{array}{c}\text { Temperatura de } \\
\text { Transição Vítrea }\left({ }^{\circ} \mathrm{C}\right)\end{array}$ \\
\hline Água & -139 \\
Proteínas solúveis & 127 \\
Lactose & 97 \\
Glicose & 31 \\
Galactose & 30 \\
\hline
\end{tabular}

Fonte: Schuck et al., 2005.

A TTg do pó está relacionada à concentração, à variação do calor específico e à TTg de todos os constituintes do produto. Dentre esses, é determinante conhecer a TTg dos produtos para fabricação de lácteos desidratados, principalmente em se tratando do soro em pó deslactosado. A transição vítrea ocorre quando a temperatura do produto é superior a sua temperatura de transição vítrea (TTg), o que pode ocorrer na secagem ou durante a estocagem (SCHUCK et al., 2005; PERRONE et. al., 2016).

A água é o principal componente que contribui para a redução da TTg, sendo caracterizada como um forte plasticizante dos lácteos desidratados (JOUPPILA et al., 1997). Dessa forma, o controle do teor de umidade do pó é de suma importância para a conservação do produto.

Dos constituintes do leite, a caseína é a que apresenta maior temperatura de transição vítrea, $132{ }^{\circ} \mathrm{C}$ (SCHUCK et al., 2005). Quando se produz queijo deslactosado, tem-se como seu derivado o soro deslactosado, sendo este, um produto de difícil secagem, já que, a produção do queijo consiste na concentração do extrato seco do leite pela coagulação da caseína, sendo assim, a ausência da caseína 
reduz a temperatura de transição vítrea do soro deslactosado (PERRONE, 2010).

Outro fator impactante na secagem de soro deslactosado é a acidez do mesmo. O soro com composição abundante em ácido lático seja por meio do tipo de queijo produzido ou pela acidez desenvolvida no tempo de estocagem, também apresenta baixa temperatura de transição vítrea, o que torna difícil o processo de secagem (PERRONE et. al., 2016).

Além disso, o soro deslactosado contém lactose (em baixas concentrações), glicose e galactose. Estes monossacarídeos apresentam uma temperatura de transição vítrea (TTg) menor que a da lactose, uma vez que, compostos com menor peso molecular apresentam menor TTg. A lactose possui $\mathrm{TTg}=97^{\circ} \mathrm{C}$, quando hidrolisada tem-se glicose com TTg $=31{ }^{\circ} \mathrm{C}$ e galactose com $\mathrm{TTg}=30{ }^{\circ} \mathrm{C}$, contribuindo para a diminuição da temperatura de transição vítrea do produto lácteo, o que dificulta ainda mais a secagem, transporte e estocagem destes produtos (ROOS, 1993; FERNANDEZ et al., 2003; PERRONE et. al., 2016). O soro com lactose hidrolisada tem um maior número de moléculas em seu estado amorfo e durante a secagem, tornase altamente higroscópico, podendo levar ao entupimento da câmara (SCHUCK et al. 2015).

Fialho et al. (2017), estudaram a caracterização termodinâmica do processo de secagem de leite com lactose hidrolisada e puderam concluir que o produto com hidrólise da lactose é mais susceptível a aderir ao equipamento devido a sua menor temperatura de transição vítrea, quando comparado ao produto comum, sem hidrólise da lactose, o que resulta numa maior perda de massa no final do processo de secagem.

Nos experimentos de Fialho et al. (2017), para ocorrer a secagem do leite em pó com lactose hidrolisada, foi utilizado diferentes condições de secagem. Na primeira, foi elaborada uma combinação de menores temperaturas $\left(115-145^{\circ} \mathrm{C}\right)$ com maiores taxas de fluxo (em média 1,4 kg.h-1 ${ }^{-1}$. Como resultado obteve uma maior atividade de água nos pós e os mesmos apresentaram umidade elevada, isso porque, as baixas temperaturas não foram suficientes para remover a água do produto. A alta umidade no pó diminui a sua temperatura de transição vítrea, como consequência, houve aglomeração dos pós. $\mathrm{Na}$ segunda condição, foi feito uma combinação de altas temperaturas $\left(130-160^{\circ} \mathrm{C}\right)$ com baixas taxas de fluxo $\left(0,3 \mathrm{~kg} \cdot \mathrm{h}^{-1}\right)$. Como resultado, os pós apresentaram coloração marrom, oriundo do excesso de produtos da Reação de Maillard. O que pode ser explicado pelo aquecimento excessivo que provavelmente permitiu a transição vítrea. Esta aumenta a mobilidade molecular devido à diminuição da viscosidade o que favorece a Reação de Maillard (ROSS et al., 1996; PEREYRA et. al., 2010; NARANJO et. al., 2013).

Ademais, os monossacarídeos glicose e galactose apresentam uma afinidade relativamente alta com a fase aquosa, o que dificulta a perda de água durante o processo de secagem. Isto posto, para obtenção dos pós com lactose hidrolisada, é necessário ser utilizado mais energia térmica para remoção da água (SCHUCK et. al., 2015).

Torres et al. (2017), em seus estudos sobre aspectos tecnológicos do leite em pó com hidrólise da lactose, testaram diferentes tratamentos de hidrólise da lactose sendo estes: $0 \%, 25 \%, 50 \%, 75 \%$ e $99 \%$ de concentrados de leite hidrolisado e puderam observar que as amostras com maior nível de hidrólise tiveram suas partículas distribuídas num maior diâmetro, o que resultou numa maior aglomeração dessas partículas e, com isso, a diminuição da capacidade de reidratação dos pós deslactosados. 


\section{AGRADECIMENTOS}

Ao CNPq, a FAPEMIG e a CAPES pelo apoio financeiro aos projetos e as bolsas de produtividade da equipe do projeto.

\section{CONSIDERAÇÕES FINAIS}

A secagem do soro deslactosado apresenta desafios para as indústrias, posto que o comportamento deste produto durante a secagem e armazenamento é diferente do soro tradicional. Possui como determinante a manutenção do estado vítreo e devido a sua composição, principalmente, o produto tornase muito difícil de secar.

Desta forma, é necessário ajustar os melhores parâmetros de operação do spray dryer com base nas características físicas e bioquímicas do soro deslactosado. Além disso, outro modo de favorecer a secagem desse produto está na alteração da composição do mesmo, com adição, por exemplo, de ingredientes que possuam uma maior temperatura de transição vítrea, o que, consequentemente, irá elevar a temperatura de transição vítrea do soro deslactosado permitindo a manutenção do seu estado vítreo. Com isso, proporcionará condições de obter um produto com atributos desejáveis durante o processamento, estocagem e consumo.

\section{REFERÊNCIAS}

ADHIKARI, K. et al. Sensory characteristics of commercial lactose-free milks manufactured in the United States. Food Science and Technology (LWT), v. 43, n. 1, p. 113-118, 2010 .

AGUILERA, J.; LILlford, P. Food Materials Science: Principles and Practice. New York: Springer, 2007. 616 p.

ALVES, M. P. et al. Estudo da viscosidade de soluções proteicas através do analisa dor rápido de viscosidade (RVA). Revista do Instituto de Laticínios Cândido Tostes, v. 69, p. 77-88, 2014

BAILEY, R. K. et al. Lactose intolerance and health disparities among African Americans and Hispanic Americans: An updated consensus statement. Journal of the National Medical Association, v. 105, n. 2, p. 112 127, 2013.

BHANDARI, B. R. et al. A semi-empirical approach to optimize the quantity of drying aids required to spray dry sugar-rich foods. Drying Technology, v. 15, n. 10, p. 2509 2525, 1997.

BRENNAN J.; HERRERA J.; JOWITT R. A study of some of the factors affecting the spray drying of concentrated orange juice, on a laboratory scale. International Journal of Food Science \& Technology, v. 6, n. 3, p. 295-307, 1971

CARIC, M. et al. Technology of Evaporators, Membrane Processing and Dryers. In: TAMIME, A. Y. Dairy Powders and Concentrated Products. United Kingdom: WileyBlackwell, 2009, p. 99-148.

CARPIN, M. et al. Caking of lactose: a critical review. Trends in Food Science \& Technology, v. 53, p. 1-12, 2016.

DAS, D.; WANG, E.; LANGRISH, T. A. Solidphase crystallization of spray-dried glucose powders: A perspective and comparison with lactose and sucrose. Advanced Powder Technology, v. 25, n. 4, 1234-1239, 2014.

DZIEZAK, J. Yeasts and yeast derivatives: applications. Food Technology, n. 2, v. 41, p. 122-125, 1987.

FERNANDEZ, E.; SCHEBOR, C.; CHIRIFE, J. Glass transition temperature of regular 
and lactose hydrolyzed milk powders. Food Science Technology (LWT), v. 36, p. 547$555,2003$.

FIALHO, T. L. et al. Lactose hydrolyzed milk powder: Thermodynamic characterization of the drying process. Drying Technology, v. 36, n. 8 , p. $922-931,2017$.

FITZPATRICK, J. J. et al. Glass transition and the flowability and caking of powders containing amorphous lactose. Powder Technology, v. 178, n. 2, p. 119-128, 2007.

GERNIGON, G.; SCHUCK, P.; JEANTET, R. Processing of Mozzarella cheese wheys and stretch waters: a preliminary review. Dairy Science and Technology, v. 90, p. 27-46, 2010 .

HYND J. Drying of whey. International Journal of Dairy Technology, v. 33, p. 52$54,1980$.

JANISZEWSKA-TURAK, E. Carotenoids microencapsulation by spray drying method and supercritical micronization. Food Research International, v. 99, p. 891-901, 2017.

JOUPPILA, K.; KANSIKAS, J.; ROOS, Y. H. Glass Transition, Water Plasticization, and Lactose Crystallization in Skim Milk Powder. Journal of Dairy Science, v. 80, n. 12, p. 3152-3160, 1997.

KESHANI, S. et al. Reducing the deposition of fat and protein covered particles with low energy surfaces. Journal of Food Engineering, v. 116, n. 3, p. 737-748, 2013.

KESHANI, S. et al. Spray drying: An overview on wall deposition, process and modeling Journal of Food Engineering, v. 146, p. 152-162, 2015.
LEITE, J. T. C.; MURR, F. E. X.; PARK, K. J. Transições de fases em alimentos: influência no processamento e na armazenagem. Revista Brasileira de Produtos Agroindustriais, v. 7, p. 83-96, 2005.

LI R.; ROOS, Y. H.; MIAO, S. Flavor release from spray-dried amorphous matrix: effect of lactose content and water plasticization. Food Research International, v. 86, p. 147155, 2016.

LULE, V. K. et al. Food intolerance: lactose intolerance. In: CABALLERO, B.; FINGLAS, P. M.; TOLDRÁ, F. Encyclopedia of food and health. Academic Press: Oxford, 2016. p. 43-48.

MASTERS, K. Spray Drying. In: MUJUMDAR, A. S. Advances in drying. Washington: Hemisphere, v. 1, p. 269-298, 1980.

MASTERS, K. Spray drying. 6th ed. New York: Longman Scientic \& Technical and John Wiley \& Sons, 2002. 725 p.

MILKOVSKA, S. S.; HOFFMANN, R. Influence of storage and heating on protein glycation levels of processed lactose-free and regular bovine milk products. Food Chemistry, v. 221, p. 489-495, 2017.

MOREIRA, T. C. et al. Elaboration of yogurt with reduced level of lactose added of carob (Ceratonia siliqua L.). Food Science and Technology (LWT), v. 76, p. 326-329, 2017.

MUJUMDAR, A. S. Handbook of Industrial Drying. $4^{\mathrm{a}}$ ed. New York: CRC Press, 2014. $1348 \mathrm{p}$.

NARANJO, G. B. et al. The kinetics of maillard reaction in lactose-hydrolyzed milk powder and related systems containing 
carbohydrate mixtures. Food Chemistry, v. 141, n. 4, p. 3790-3795, 2013.

NOELLO, C. et al. Spray dried microparticles of chia oil using emulsion stabilized by whey protein concentrate and pectin by electrostatic deposition. Food Research International, v. 89, 549-557, 2016.

NORWOOD, E. A. et al. Crucial role of remaining lactose in whey protein isolate powders during storage. Journal of Food Engineering, v. 195, 206-216, 2017.

PATEL, K. et al. One-dimensional simulationofco-current, dairy spray drying systems pros and cons. Dairy Science \& Technology, v. 90, n. 2-3, p. 181-210, 2010.

PEREYRA, G. A. S. et al. Maillard Reaction Kinetics in Milk Powder: Effect of Water Activity at Mild Temperatures. International Dairy Journal, v. 20, n. 1, p. 4045,2010 .

PERrone, I. T. Soro do Leite: Concentração, Cristalização da Lactose e Secagem. 2010. 95 f. Tese (Doutorado em Ciência e Tecnologia de Alimentos) - Universidade Federal de Viçosa, Viçosa, 2010.

PERRONE, I. T.; PEREIRA, J. P. F.; CARVALHO, A. F. Aspectos tecnológicos da fabricação de soro em pó: uma revisão. Revista do Instituto de Laticínios Cândido Tostes, v. 66, n. 380, 2011.

PERRONE, I. T. et al. Isotermas de sorção e caracterização físico-química de lácteos desidratados. Revista do Instituto de Laticínios Cândido Tostes, v. 68, n. 395, p. 33-38, 2013.

PERRONE, I. T. et al. Soro em pó: estado vítreo e condições de operação do spray dryer.
Revista do Instituto de Laticínios Cândido Tostes, v. 71, n. 2, p. 106-118, 2016.

POOZESH, S. et al. Understanding the process-product-performance interplay of spray dried drug-polymer systems through complete structural and chemical characterization of single spray dried particles. Powder Technology, v. 320, p. 685-695, 2017.

REFSTRUP, E.; BONKE, J. Plant and Equipment/Milk Dryers: Drying Principles. In: FUQUAY, J. W.; FOX, P. F; Mc SWEENEY, P. L.H. Encyclopedia of Dairy Sciences. $2^{\mathrm{a}}$ ed. London: Elsevier, 2011. p. 208-215.

RONG, Q. I. A. O. et al. Milk consumption and lactose intolerance in adults. Biomedical and Environmental Sciences, v. 24, n. 5, p. 512-517, 2011

ROOS, Y. Melting and glass transitions weight carbohydrates of low molecular. Carbohydrate Research, v. 238, p. 39-48, 1993.

ROOS, Y. H.; JOUPPILA, K.; ZIELASKO, B. Non-Enzymatic browning-induced water plasticization - glass transition temperature depression and reaction kinetics determination using DSC. Journal of thermal analysis, n. 47, p. 1437-1450, 1996.

RUIZ, M. A. I. et al. Presence of mono-, diand galactooligosaccharides in commercial lactose-free UHT dairy products. Journal of Food Composition and Analysis, v. 28, n. 2, p. 164-169, 2012.

SADEK, C. et al. Buckling and collapse during drying of a single aqueous dispersion of casein micelle droplet. Food Hydrocolloids, v. 52, 161-166, 2016.

SÁNCHEZ, M. D. R. H.; CUVELIER, M. E.; 
TURCHIULI, C. Effect of $\alpha$-tocopherol on oxidative stability of oil during spray drying and storage of dried emulsions. Food Research International, v. 88, 32-41, 2016.

SANDER, A.; PENOVIĆ, T. Droplet size distribution obtained by atomization with two- fluid nozzles in a spray dryer. Chemical Engineering Technology, v. 37, n. 12, p. 2073-2084, 2014.

SANTOS, A. A. C. et. al. Avaliação físicoquímica e comportamento higroscópico de goiaba em pó obtida por spray-dryer. Revista Ciência Agronômica, n. 3, v. 45, p. 508-514, 2014.

SCHUCK, P. Spray Drying of dairy products: state of the art. Lait, v. 82, p. 375-382, 2002.

SCHUCK, P. et al. Séchage de lactosérum et dérivés: role du lactose et de La dynamique de l'eau. Le Lait, v. 84, p. 243-268, 2004.

SCHUCK, P. et al. Water activity and glass transition in dairy ingredients. Lait, v. 85, p. 295-304, 2005.

SCHUCK, P. et al. Relative humidity of outlet air: the key parameter to optimize moisture content and water activity of dairy powders. Dairy Science and Technology, v. 88, n. 1, p. 45-52, 2008.
SCHUCK, P. et al. Drying by desorption: A tool to determine spray drying parameters. Journal of Food Engineering, v. 94, n. 2, p. 199-204, 2009.

SCHUCK, P. et al. Energy consumption in the processing of dairy and feed powders by evaporation and drying. Drying Technology, v. 33, n. 2, p. 176-184, 2015.

SCHUCK, P. et al. Recent advances in spray drying relevant to the dairy industry: A comprehensive critical review. Drying Technology, v. 34, n. 15, p. 1773-1790, 2016a.

SCHUCK, P. Material Didático do Curso: Concentration, Crystallization, Spray Drying e Rehydration. Viçosa: UFV, 2016 b.

TORRES, J. K. F. et al. Technological aspects of lactose-hydrolyzed milk powder. Food Research International, v. 101, p. 45-53, 2017.

TROISE, A. D. et al.. The quality of low lactose milk is affected by the side proteolytic activity of the lactase used in the production process. Food ResearchI nternational, v. 89, p. 514-525, 2016.

WOO, M. et al. Controlling food powder deposition in spray dryers: Wall surface energy manipulation as an alternative. Journal of Food Engineering, v. 94, n. 2, p. 192-198, 2009. 